\title{
A STATE-OF-THE-ART WASTE MANAGEMENT SOLUTION: SMART BINS/E-BINS
}

\author{
Zelieus Namirian \\ Department of Mechanical Engineering \\ Mumbai University, Mumbai, India
}

\begin{abstract}
In the past few a long time there may be a zoom inside the price of urbanization and therefore there may be a demand for property city improvement plans. currently, victimization new age era and strategic technique, the assemble of smart towns are springing up all around the arena. a realistic city is incomplete at the same time as not a clever waste control system. This paper describes the appliance of our model of "clever Bin" in dealing with the waste assortment machine of a whole metropolis. The network of sensors enabled smart boxes linked via the cellular community generates an outsized amount of data, that is similarly analyzed and pictured at the actual time to recognize insights concerning the status of waste around the town. This paper conjointly objectives at encouraging extra analysis inside the subject matter of waste control.
\end{abstract}

Keywords - Innovation, Smart Bins, Automatic, IoT, Waste Management, Smart cities, waste assortment system, Indian example of Insolent Container/Smart Bin.

\section{INTRODUCTION}

\section{A. Economics and Numbers Involved}

The Republic of India being the creating nation that it is, the per capita squander era is expanding by $1.3 \%$ per annum. India produces 42.0 million loads of metropolitan strong squander yearly. The general sum of strong squander created in urban ranges per day of the nation is 1.15 hundred thousand tons. The normal squander era rate is 0.4 weight unit per capita per day in 0.1 million and towns. Urban local bodies spend around Rs.500/- to Rs.1500/- per ton on strong squander administration of which, $60-70 \%$ of the number is for the gathering alone. The rough offering of the collected squander is practiced in most of the cities, though several have isolation-related utilization units. Much obliged to destitute administration of household squander from family units, the setting is getting debasement day by day and is on the rise. [2]

\section{B. Effect of Waste and Improper Management -}

Unpleasant waste, if disposed of improperly, can present an environmental risk and be harmful to the environment. When these irregularities fall into space, they can break lines and cause cancer-related illnesses. The result of this fall is global warming. Pollution makes compost difficult to remove from the soil surface, which can lead to the formation of rain which is harmful to plant life. This also affects migration. Solid waste

\author{
Zarieus Namirian \\ Department of Economics \\ Symbiosis International University, Pune, India
}

that falls into streams and drains will block drains. This can lead to flooding. At the same time, the pollution also affects the drainage system, making it difficult to obtain crops [1,4].

\section{Aim and Objective -}

Our project aims to undertake and do precisely an equivalent, i.e. the segregation of waste into 3 major categories;
i. Metallic,
ii. Plastics
iii. Biodegradable.

The separate waste from homes will then be directly sent to process units instead of the segregation plants. This protects a lot of the human and economic resources of the govt.

\section{PROPOSED Algorithm}

\section{A. Objectives -}

We tend to propose to develop a "Smart Bin", that is capable of segregating waste automatically once it's drop into the bin, thereby reducing the human efforts required to segregate waste and put together produce Republic of Asian country a cleaner place to live in. The wise bin aims at segregating waste at the provision itself as initiated by our government recently. It eliminates the human interference for the segregation of waste and put together the necessity of fixing huge segregation units in each district of the country. This protects different it slow and money for the govt. It additionally helps to prevent setting pollution which can be caused in and around the waste segregation units. $[8,11]$

\section{B. Methodology -}

A small scale enterprise (SAI businesses) having important drawback relating to fee of cloth coping with gadget, they would not use automatic device in order that they use manually machines. The fabric coping with like lifting of raw materials, switch the completed product to final degree, switch the only product from one department to opportunity branch so overall price wanted for fabric managing is boom. This fee affected on profit of corporation so that we tend to avoid this downside we discover solution to beat on pinnacle of trouble with the help of realistic containers. 
International Journal of Engineering Applied Sciences and Technology, 2021

Vol. 5, Issue 10, ISSN No. 2455-2143, Pages 277-280

Published Online February 2021 in IJEAST (http://www.ijeast.com)

\begin{tabular}{|c|c|c|}
\hline $\begin{array}{c}\text { Serial } \\
\text { No. }\end{array}$ & Component & Use \\
\hline 1 & Acrylic sheet & For the body of the bin \\
\hline 2 & G I sheet & For metal separation \\
\hline 3 & PVC coated mesh & For plastic separation \\
\hline 4 & Circular permanent magnet & For metal separation \\
\hline 5 & 300 rpm Geared DC Motor & For sieve system \\
\hline 6 & 35 mm Gear & For sieve system \\
\hline 7 & 3 " hinges & For the fabrication \\
\hline 8 & Bolts, Nut \& Washer & For the fabrication \\
\hline 9 & Thread & For the sieve system \\
\hline 10 & Magnetic lock & For the door \\
\hline 11 & Connecting wires & Electrical connections \\
\hline 12 & L Clamps & For the fabrication \\
\hline 13 & Door knobs & For easy handling \\
\hline 14 & Jet air blower & For separation of waste \\
\hline
\end{tabular}

Table 1: Components used

C. Design of the Model -

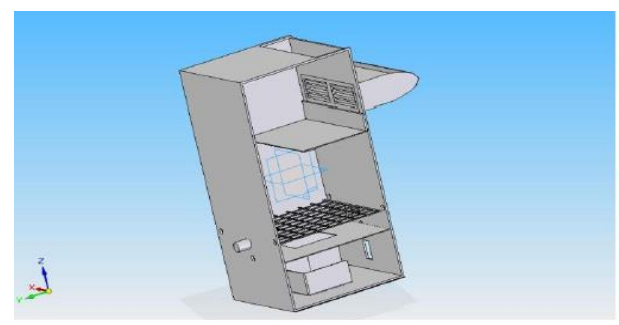

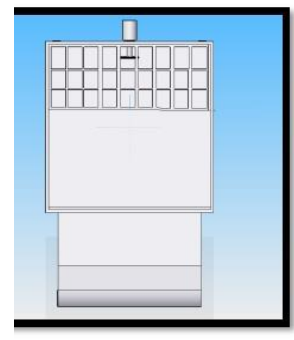

Figure 2: Top view

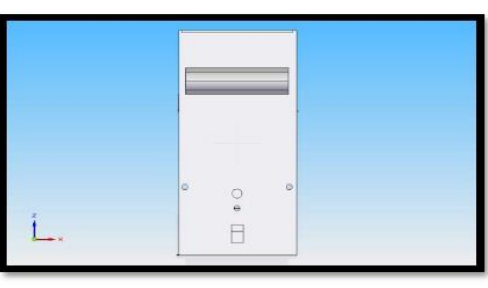

Figure 3: Side view

\section{Fabricated Model -}

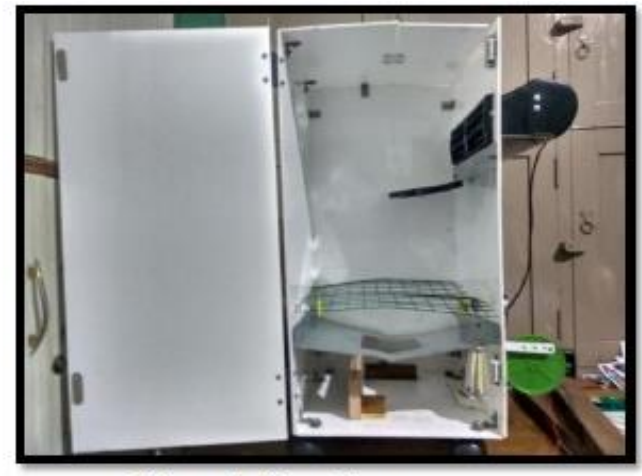

Figure 4: Front view

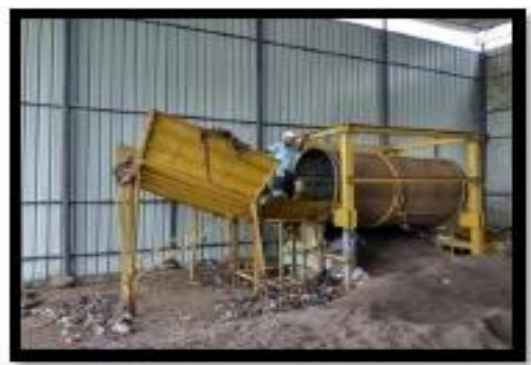

Figure 5: Screening machine used to turn the waste

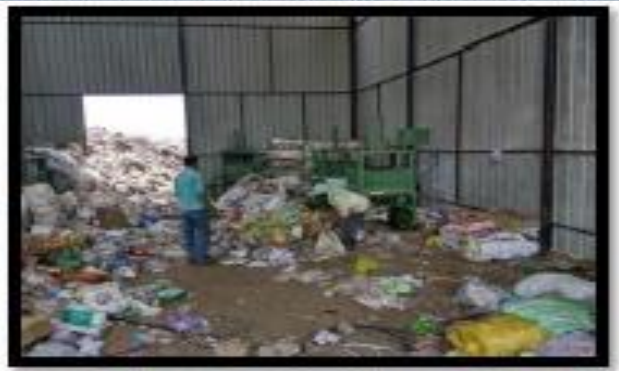

Figure 6: Plastic compression

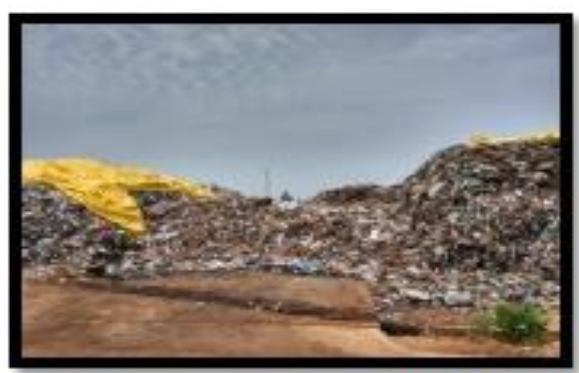

Figure 7 Waste dumped in the alloted place

\section{EXPERIMENT AND RESULT}

\section{A. Operational Procedure -}

In operation, any waste (Magnetic cloth, plastic, and biodegradable) is trashed into the bin thru the door. It enters into the number one compartment of the bin anyplace the magnetic materials are being segregated. This compartment includes a GI 
Sheet hooked up to the acrylic walls of the practical bin at one finish and opened on the alternative aspect. The magnets positioned at very cheap GI sheets entice the Magnetic materials and there through magnetic materials get amassed. [3, 6] besides, the plastic and bio-degradable materials are blown off to the second compartment through the blower this is placed adjacently. The substances input the second compartment which consists of a mesh being vibrated by using the tools coupled to the in-gear dc motor. The substances as currently as they fall on the mesh are subjected to vibration which reasons the separation of plastic and bio-degradable materials. The biodegradable materials are made to symbolize the third compartment. Right here a piston arrangement is shaped to compress the perishable waste that falls into the field placed inside the $1 / 3$ degree of the bin. However successive segregation takes vicinity in our "clever bins". [10, 14]

\section{B. Results -}

The potency of segregation would not amend whether or now not we tend to unload the waste one at a time or suddenly into the sensible bin. consequently, practical boxes may be positioned at homes, places of work, and residences to segregate waste at the supply successfully. however, we examine that their many improvements wished on the diverse tiers for segregating plastic and paper so we're \{able to $\}$ convey home the 1st Baron Verulam one hundred performance in the segregation technique.

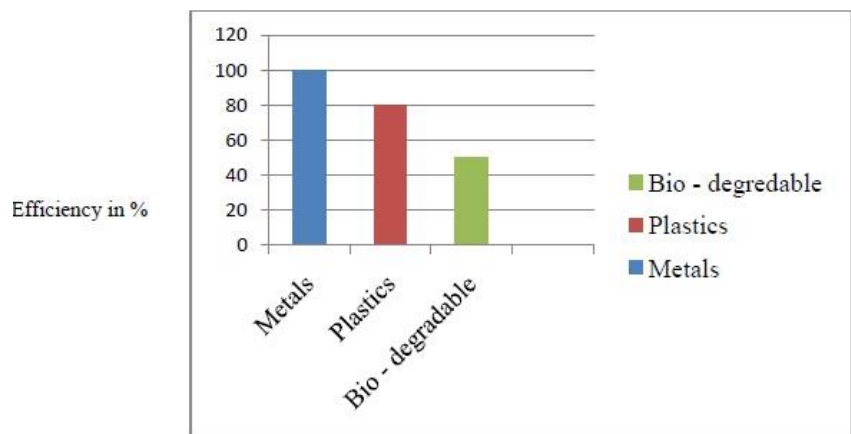

The consequent perceptions were made all through the isolation:

1. Within the moment organize, littler plastics are essentially passing through the work and getting into the biodegradable compartment.

2. Within the third arrangement, bigger biodegradable squanders do not appear to be entering the chamber as bigger particles are not able to involve the work.

3. Though sensible containers are competent in isolating the common sorts of dry squanders, it falls flat to isolate the damp squander, restorative and risky squanders.

4. The isolation strategy is mechanized, but the gathering of the squander when isolating needs to be collected physically. [12]

\section{Scope for Future Work -}

As an associate extension to the projected sensible Bin, a shortlived and technically additional advanced version is meant to segregate harmful waste from nuclear and chemical plants. This might be a secure improvisation over existing strategies that involve humans in harmful waste collection. This might facilitate reduce death rate because of exposure to nuclear radiation or chemical toxins. Besides being a time-saving alternative, it would be a secure resource to use. Enhancements created within stages 2 and three of the sensible bin, i.e. segregating of plastics and perishable wastes will cause additional economical product. More suitable gum if employed within the ultimate compartment of the sensible bin is prepared to make compact briquettes from the biodegradable waste collected throughout segregation. Conjointly programs are often enforced to the smart bins for storing and transferring waste segregation connected information between numerous agencies associated with waste segregation. [5, 7]

\section{CONCLUSION}

As a result of the high rates of waste disposal per person, per day within the country, there arises a dire necessity to hunt an alternative. The prevailing system of waste collection is extremely monotonous and smitten by human labor. The absence of someone to gather the waste from the neighborhood adversely affects the immediate surroundings, resulting in an unsanitary environment. In today's world, time is another limiting factor. This prevailing situation compels the lifestyles of a probable substitute that could resolve the shortcomings of the present technique of waste series. A sensible Bin in each house or place of business will take away the requirement for human interference for the gathering of waste for segregation cause. Conjointly a smart bin on the supply of waste generation gets rid of the want for putting in giant regions of waste segregating units. This can be saving the government whenever and coins wished for setting up and keeping the gadgets.

\section{REFERENCE}

[1] Archangel Alexander, John Walkenbach, "Microsoft surpass Dashboards \& Reports", Wiley; Second edition, twenty eight June 2013. (Book style)

[2] Yann Glouche, Paul Couderc. a sensible Waste Management with SelfDescribing objects. Leister, Wolfgang and Jeung, Hoyoung and Koskelainen, Petri. The Second International Conference on sensible Systems, Devices and Technologies (SMART'13), Jun 2013, Rome, Italy. 2013. (Conference proceedings)

[3] Foday Pinka Sankoh, Xiangbin Yan, Quangyen Tran on "Environmental and Health Impact of Solid Waste Disposal in Developing Cities: A Case Study of Granville Brook Dumpsite, Freetown, Sierra Leone," on Journal of 
Environmental Protection, 2013, 4, 665-670. (Journal or magazine citation)

[4] Anthopoulos, L. (2019). Smart city emergence: Cases from around the world. Elsevier.

[5] Bloss, R. (2006). Smart robot that picks parts from bins. Assembly Automation, 26(4), 279-282. https://doi.org/10.1108/01445150610705182

[6] Digital dustbin - Smart bins for smart cities. (2020). International Journal of Innovative Technology and Exploring Engineering, 9(7S), 60-65. https://doi.org/10.35940/ijitee.g1021.0597s20

[7] Ghafoor, K. Z., Curran, K., Kong, L., \& Sadiq, A. S. (2020). Security and organization within IoT and smart cities. CRC Press.

[8] Guntupalli, S. R. (2019). Smart bins for garbage collection using IoT. International Journal for Research in Applied Science and Engineering Technology, 7(3), 1016-1022. https://doi.org/10.22214/ijraset.2019.3179

[9] Haque, K. F., Zabin, R., Yelamarthi, K., Yanambaka, P., \& Abdelgawad, A. (2020). An IoT based efficient waste collection system with smart bins. https://doi.org/10.36227/techrxiv.12455936.v1

[10] Jaid Jim, A. A., Kadir, R., Mamun, M. A., Nahid, A., \& Ali, M. Y. (2019). A noble proposal for internet of garbage bins (IoGB). Smart Cities, 2(2), 214-229. https://doi.org/10.3390/smartcities2020014

[11] Parmar, S., Jain, N., Negi, S., Prajapati, M., \& Vaish, I. (2020). IOT-based smart bins. International Journal of Computer Applications, 177(39), 42-44. https://doi.org/10.5120/ijca2020919894

[12] Smart waste management and predicting bins with high waste index. (2020). International Journal of Innovative Technology and Exploring Engineering, 9(7), 482-485. https://doi.org/10.35940/ijitee.g5001.059720

[13] Specification for litter bins. (n.d.). https://doi.org/10.3403/00071587u

[14] Tomar, P., \& Kaur, G. (2019). Green and smart technologies for smart cities. CRC Press. 